
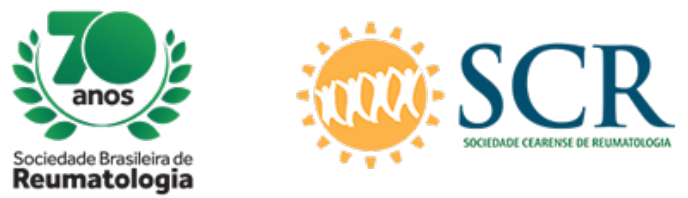

\title{
ERITEMA ELEVATUM DIUTINUM IN PATIENTS WITH RHEUMATOID ARTHRITIS: CASE REPORT
}

Querolai Gomes Gadelha (HUMAP, Campo Grande, MS, Brasil), Carolina Yume Arazawa (HUMAP, Campo Grande, MS, Brasil), Renato Furtado Tavares (HUMAP, Campo Grande, MS, Brasil), Leonardo Perera Won Muhlen (HUMAP, Campo Grande, MS, Brasil), Débora Tobaldini Russo (HUMAP, Campo Grande, MS, Brasil), Amanda Pereira Rodrigues Costa (HUMAP, Campo Grande, MS, Brasil)

\section{BACKGROUND}

Erythema elevatum diutinum (EED) is a rare chronic dermatosis, classified as a leukocytoclastic vasculitis of small vessels of the dermis. The name EED was first used by Radcliff-Crocker and Williams, who separated the disease into two groups: the Bury subtype associated with rheumatic diseases, particularly affecting young women, and the Hutchinson subtype, which tends to affect with more frequency elderly men. Its etiology is still unknown, but it is believed to result from the deposition of immunocomplexes in the perivascular dermis, secondary to infections, neoplasias or autoimmune diseases, inducing an inflammatory cascade that would damage the vessel wall and consequent fibrosis.

\section{CASE REPORT}

An 44-year-old woman presented with symmetrical polyarthritis, associated with movement limitation and morning stiffness, started in 2016. She was referred to the HUMAP Rheumatology service for diagnostic investigation. After other hypotheses were excluded, the diagnosis of rheumatoid arthritis was established, with an increase in inflammatory tests, anti-CCP and Rheumatoid Factor in high titers. Prednisone and Methotrexate therapy was started, progressing with partial improvement of the joint frame. Two years after the onset of the joint frame, the patient noticed painful erythematous papules and nodules on the lower limbs. The patient was referred to the HUMAP Dermatology service, and a skin biopsy was performed. The patient had a perivascular lymphoplasmahistiocytic inflammatory infiltrate with a vascular disorders of leukocytoclastic pattern and eosinophils randomly distributed, compatible with EED. Treatment with Dapsone was initiated with improvement of cutaneous lesions. Methotrexate was suspended due to drug interaction with Dapsone and anti-TNF therapy with Certolizumab was started.

\section{CONCLUSION}

EED is a rare chronic disease that manifests itself with plaques, papules and erythematous-purple nodules which, in most cases, assume a symmetrical distribution, preferably located on the extensor surfaces. Arthralgia is the most prevalent systemic symptom present in up to $40 \%$ of patients. In some cases, arthritis is important and associated with elevated inflammatory proofs.

It has an association with several systemic diseases, including autoimmune, infectious and haematological malignancies, and some concomitant rheumatologic diseases are common. EED cases have been associated with Rheumatoid Arthritis, Recurrent Polychrome, Systemic Lupus Erythematosus, Sjogren's Syndrome, and Juvenile Idiopathic Arthritis.

Therefore, the presented case is relevant, since it evidences the importance of knowing the cutaneous manifestations of EED. This should be investigated in patients with rheumatoid autoimmune diseases, such as rheumatoid arthritis, and characteristic cutaneous manifestations. 